\title{
A mortal accident caused by a broken toilet seat cover
}

\author{
Yildiray Zeyfeoglu ${ }^{1}$, M. Sunay Yavuz ${ }^{1}$, Tarik Ulucay ${ }^{1}$, M. Ziya Kir ${ }^{1}$, Faruk Aydin ${ }^{1}$, Ilknur \\ Kahraman $^{1}$, Gonca Tatar ${ }^{1}$, Zafer Karadeniz ${ }^{2}$, Mustafa Dalgic ${ }^{2}$
}

\begin{abstract}
According to hospital records, a 36 years old, $1.75 \mathrm{~m}$ in length, average weight man was brought to Izmir Bozyaka Training and Research Hospital by 112 ambulance at 01/07/2011, 21:20 PM with an injury caused by fracture of toilet seat cover when he was sitting. In the examination, a $20 \mathrm{~cm}$ length oblique section with active bleeding was seen at the right gluteal region and superior gluteal artery and vein injury was detected. Department of orthopedics controlled bleeding, patient admitted to intensive care unit but he was accepted as dead at 06:35 AM.
\end{abstract}

Keywords: Superior Gluteal Artery, Vein Injury

\section{Introduction}

According to World Health Organization (WHO), an accident is an incident that occurs unwillingly and causes physical and mental damage by a sudden external force. Accidents are generally classified according to the locations where they occur $[1,2]$. An accident that occurs in a home or around it are named as home accident and these are thought as a serious public health problem due to common related injuries [1]. Injuries can be categorized by intent: unintentional or 'accidental' and intentional. Unintentional are road traffic injuries, poisoning, drowning, falls and burns. Injuries can also be classified by place and activity e.g. home or leisure accidents, occupational $[3,4]$. Accidents are a major cause of death, injury, and lost productivity, and they impose a heavy financial burden [5]. Injuries impose one of the greatest health risks in terms of mortality and morbidity among adolescents and young adults [6]. Worldwide, injuries are leading causes of death in all age groups [7].

In this study, case ended with death by a broken toilet seat cover is presented and it is aimed to review preventive measures to avoid these accidents.

Case

According to hospital records, a 36 years old, $1.75 \mathrm{~m}$ in length, average weight man was brought to Izmir Bozyaka Training and Research Hospital by 112 ambulance at 01/07/2011, 21:20 PM with an injury caused by fracture of toilet seat cover when he was sitting. In the examination, a 20 $\mathrm{cm}$ length oblique section with active bleeding was seen at the right gluteal region and superior gluteal artery and vein injury was detected. Department of orthopedics controlled bleeding, patient admitted to intensive care unit but he was accepted as dead at 06:35 AM.

Autopsy was performed by Division of Council of Forensic Medicine in Izmir. At the external examination; it is seen that there are surgical sutures in the right gluteal region (Picture 1). Autopsy showed bleeding from right superior gluteal artery and vein injury as the cause of death (Picture 2).

Specimens were taken for toxicological analysis. On toxicological analyze, there is no toxic substance at blood and urine.

\section{Discussion}

Home accidents are an important and under-estimated public health issue and an important and under-estimated housing issue. Unintentional injuries within the home environment have not been recognized to the same extent as road traffic or occupational injuries [8,9]. The majority of injuries of children under five and people aged 75 and over occur in the home [10, 11].

According to Kaz'ar $G$ et al [12], home accidents constitute approximately the half of all accidents and show an increasing tendency. $35 \%$ of all injuries occurred within home environments in Sweden [12] and therapeutic measures for a home 
accident victim costs approximately 1,300 USD annually in Norway [13] and, in France, $10 \%$ of all public health costs is caused by home accidents [2].

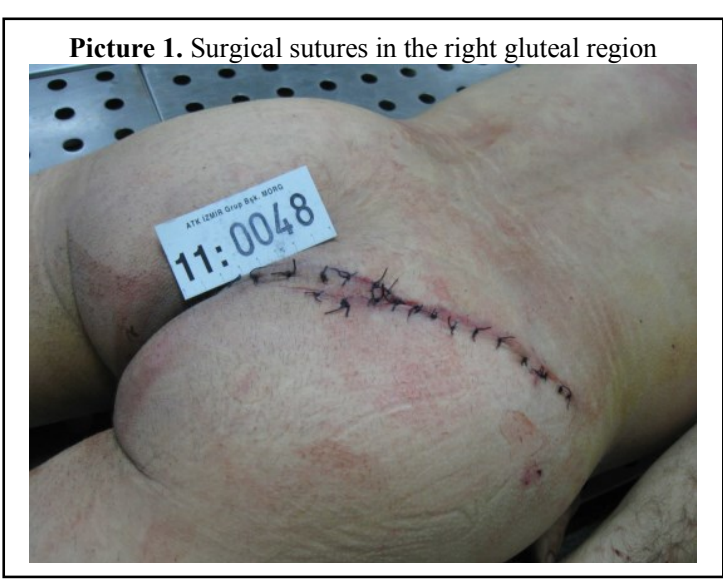

The home environment is an important setting for unintentional injuries. About one fifth of all fatal unintentional injuries take place in a home [14]. In the Netherlands each year, approximately 17 injuries per 100 inhabitants are medically treated; three-quarters of these are home and leisure accidents [7].

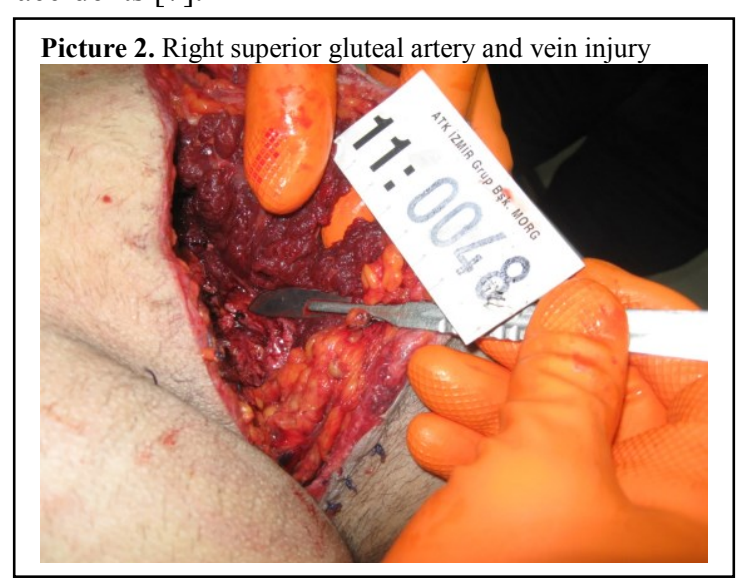

In the New Zealand it was estimated that there was an associated increase in the odds ratio of a home injury occurrence of $22 \%$ (16). In Turkey, various studies show that home accidents account for $18-25 \%$ of all accidents [1]. The proportion of fatal home accidents among all fatal accidents in the UK in 1990 was $2.5 \%$, while in Turkey this was $5.7 \%[1]$.

Falls were most common followed by burns, electrocutions and poisonings [2, 15]. The toilet was the most common site of home accident followed by the sitting room, the kitchen, the bedroom and the dining room [15]. In our case, accident was occurred in the toilet.

The literature on the prevention of home accidents mention various measures, mainly defining sources of potential danger according to the psychological and motor development of children appreciating that all children, regardless of the age, are at enhanced risk for home accidents, education of parents and attending personal, home- safety measures on the basis of legal regulations, home-designing and production of safe household articles, special safety regulations for household equipment's and environmental conditions, labeling of chemical agent containers, supervision of homesafety measures by inspectors and financial support for families to safety-improving measures [2].

Fatal home accidents have increased seriously in recent years. To prevent home accidents, with some behavioral changes, home equipment's and products must be produced appropriately for home security.

Preventing home accidents with essential measures will not only avoid lots of many injuries and deaths but will also avoid unnecessary economic losses in health expenditures.

Financial Support: This research received no specific grant from any funding agency, commercial or not-for-profit sectors

Conflict of Interest: The authors declared that they had no conflicts of interest.

\section{References}

[1] Hamzaoglu O, Ozkan O, Janson S. Incidence and causes of home accidents at Ankara Cigiltepe apartments in Turkey. Accident; analysis and prevention. 2002;34(1):123-8.

[2] Asirdizer M, Yavuz MS, Albek E, Canturk G. Infant and adolescent deaths in Istanbul due to home accidents. The Turkish journal of pediatrics. 2005;47(2):141-9.

[3] Preventing children accidents and improving home safety in the European region. Identifying means to makedwellings safer. Report of a WHO expert meeting, Bonn. 2005-May 30-31.

[4] Runyan CW, Casteel C, Perkis D, Black C, Marshall SW, Johnson RM, et al. Unintentional injuries in the home in the United States Part I: mortality. American journal of preventive medicine. 2005;28(1):73-9.

[5] Farchi S, Camilloni L, Giorgi Rossi P, Chini F, Borgia P, Guasticchi G. Home injuries mortality: sensitivity and specificity analysis of different data sources and operative definitions. Accident; analysis and prevention. 2007;39(4):716-20.

[6] Ahmed N, Andersson R. Differences in cause-specific patterns of unintentional injury mortality among 15-44year-olds in income-based country groups. Accident; analysis and prevention. 2002;34(4):541-51.

[7] Mulder S, Blankendaal F, Vriend I, Schoots W, Bouter L. Epidemiological data and ranking home and leisure accidents for priority-setting. Accident; analysis and prevention. 2002;34(5):695-702.

[8] Gulliver P, Dow N, Simpson J. The epidemiology of home injuries to children under five years in New Zealand. Australian and New Zealand journal of public health. 2005;29(1):29-34. 
[9] Lindqvist K, chelp L, Timpka T. Home injuries in a Swedish municipality- consequences and costs Safety Science. 1999;31:19-29.

[10] Turner S, Arthur G, Lyons RA, Weightman AL, Mann MK, Jones SJ, et al. Modification of the home environment for the reduction of injuries. The Cochrane database of systematic reviews. 2011(2):CD003600.

[11] Lyons RA, Newcombe RG, Jones SJ, Patterson J, Palmer $\mathrm{SR}$, Jones P. Injuries in homes with certain built forms. American journal of preventive medicine. 2006;30(6):513-20.

[12] Kaz'ar G, Ga'al P, K'osa J. Significance of home accidents. Magy Traumatol Ortop Kezseb Plasztikai Seb. 1994:37:263-270. Abstract.
[13] Kopjar B, Wickizer TM. Population-based study of unintentional injuries in the home. American journal of epidemiology. 1996;144(5):456-62.

[14] Runyan CW, Perkis D, Marshall SW, Johnson RM, Coyne-Beasley T, Waller AE, et al. Unintentional injuries in the home in the United States Part II: morbidity. American journal of preventive medicine. 2005;28(1):80 7.

[15] Lee VM, Wong TW, Lau CC. Home accidents in elderly patients presenting to an emergency department. Accident and emergency nursing. 1999;7(2):96-102. 